\title{
Halfway there - The evolution of local alcohol control in California. Part II: Stages and factors in development, 1980-2015
}

\author{
Friedner D. Wittman ${ }^{1,2}$ \\ ${ }^{1}$ President, CLEW Associates, Berkeley, California, United States \\ ${ }^{2}$ Affiliated Scientist, Alcohol Research Group, Public Health Institute, Emeryville, California, United States
}

\begin{abstract}
From 1980 to 2015 California cities have been increasing their capacity for preventive local control to reduce harms attributable to retail alcohol outlets. We describe a four-stage process that has evolved from reactive zoning to preventive zoning. Starting about 1980, communities turned to local zoning following the California Alcohol Beverage Control (ABC) Department's struggles to stem growing problems with new types of rapidly proliferating outlets in rapidly-changing cities. (See Wittman [2016] for the function of local zoning in the California Alcoholic Beverage Control Department (ABC) system for licensing retail alcohol outlets). Community coalitions teamed with local public officials to reduce problems through "local control" ordinances based on conditional-use permits for retail alcohol outlets. Working in coordination with ABC licensing procedures, cities learned to use their zoning ordinances to draw effective boundaries for outlet location and type of setting, to limit outlet density, and to impose preventive restrictions on outlet design and operation. The California Department of Alcohol and Drug Programs and the California alcohol policy advocacy community helped develop local control into a statewide movement. This paper reviews local control's statewide progress to date and considers its prospects for future development to prevent harm in California cities. We conclude cities are about halfway to achieving harm-reduction benefits available from self-sustaining regulatory infrastructures grounded in participatory administration of local land-use law.
\end{abstract}

\section{Introduction}

This paper continues the introductory discussion of California's system for state licensing and local land-use oversight (local control) described in Wittman (2016). The evolution of local control follows a four-stage progression of development described below. The discussion summarizes cities' development history of preventive local control to date and issues for further development of preventive zoning to achieve local control's full potential for reducing harm and protecting public health and safety.

A four-stage progression to increase local oversight has been occurring in California. Each stage continues to operate while succeeding stages build on gains of previous stages.

- Stage 1: Reactive zoning. Level 1 "on demand" zoning applies to retail alcohol outlets without special review, requiring post-hoc public management of problems with alcohol outlets primarily through law-enforcement. This approach was used exclusively from the late 1950s into the 1970 s, and continues at this writing de facto in many cities and in most counties;
- Stage 2: Problem-oriented zoning. Level 2 Conditional Use Permit (CUP) zoning applies to reduce risks in future outlets and in existing outlets that seek major expansions. This approach, typically known as "local control” zoning, developed during the late 1970s and 1980s;

- Stage 3: Oversight zoning. Level 3 Deemed Approved Ordinance (DAO) zoning applies to currently-operating outlets that create harm, including "grandfathered" or pre-existing outlets operating under Level 1 use permits prior to passage of a CUP ordinance. This approach extends problem-oriented zoning, to mitigate longstanding problems with intractable outlets. Created during the 1990s, oversight zoning is in middle stages of development at this writing; and

- Stage 4: Preventive zoning. Public-management zoning that actively monitors adherence by all local retail alcohol outlets to current community standards for public health and safety. This approach emerged in about 2000 and is in early stages of development at this writing. 
California's evolution toward preventive local control for retail alcohol outlets is driven by each city's voluntary adoption of a local control ordinance, written by each city moving at its own pace. Stage 1 zoning is a default condition - state law requires that all California cities begin with Stage 1 zoning. Cities dissatisfied with results of Stage 1 zoning to manage problems with outlets adopt Stage 2 (Level 2 CUP zoning) and Stage 3 (Level 3 DAO zoning) for alcohol outlets as problem-solving measures in response to community pressure. Movement toward preventive local control begins with advocacy by a constituency of concerned groups in the local community (e.g., a local coalition of organizations, neighbors, groups concerned about health, safety, and youth). This constituency puts pressure on city government agencies responsible for oversight of retail alcohol outlets, such as police, planning/zoning, housing and neighborhood services, code compliance, and the city attorney's office. City government's relationship to pressures from the advocacy community and to demands of the outlet operators involves a complex process of mediating between private commercial interests and public health and safety (Morgan, 1980, 1988).

At this writing, the forward edge of this shift can be characterized as early-middle adoption of Stage 3 oversight zoning and in the earliest stages for adoption of Stage 4 preventive zoning. Most California cities (we estimate about $80 \%$ ) have adopted Level 2 CUP ordinances and are putting them to work. An unknown number of cities (maybe 50) have adopted Level 3 DAO ordinances that specify clear community performance standards for retail alcohol operation and management. We know of only a few cities that are developing management practices and preventive surveillance systems to fully implement their DAOs.

No requirements from the State of California force local jurisdictions to adopt preventive local control ordinances for retail alcohol outlets. However, pressure is exerted through two state agencies and the California community of researchers, advocates, and service providers concerned about alcohol and other drug (AOD) problems. This pressure emerged in the form of support to help a few pioneer cities apply local zoning controls to retail alcohol outlets when state Alcohol Beverage Control (ABC) oversight faltered. These sources of support are described briefly below. Next we describe what the pioneering Stage 1 cities accomplished, followed by a review of advances in the developmental progression outlined above. We conclude with a discussion of the current state of development and comment on next steps to resume the advance, which we hope is only temporarily stalled, to realize the full potentials of preventive local control for retail alcohol outlets.

Prologue: State ABC control from 1957 to the early 1970s. As noted in Wittman (2016), the California ABC was established as a reform agency in the 1950s to eliminate corruption and crime that had overtaken retail licensing in the state. Reform efforts succeeded, and by the late 1970s California cities were receptive to burgeoning growth of new retail outlets, including many restaurants and bottle shops. The ABC had not been designed to handle a rapid expansion in numbers and in novel types of new outlets. New kinds of problems emerged related to outlet densities and to behavior issues in changing norms regarding drinking and drug use. Cities, frustrated with the performance of an out-flanked $\mathrm{ABC}$ and their own local law enforcement, turned to local zoning law.

\section{Three sources of support}

In the 1970s, cities were essentially on their own to deal with certain problems related to retail alcohol outlets. Starting in about 1980, help came from three sources. The California Alcoholic Beverage Control Department (state $A B C$ ) provided the regulatory framework of state law in which local control could operate as described in Wittman (2016). The California alcohol research and advocacy community, particularly through the Alcohol Research Group and the Prevention Research Center, helped draw an actionable nexus between health and safety problems attributable to retail alcohol outlets, and explored community planning methods to apply the new linking information. This research helped the California alcohol policy advocates put the new information to work for local zoning. The California Department of Alcohol and Drug Programs (state DADP) provided substantial support for transmitting this research and advocacy knowledge to the field through training, technical assistance, and funding. This assistance helped local community groups pressure public officials to adopt Level 2 and Level 3 zoning and related oversight measures.

The California Department of Alcoholic Beverage Control. The ABC's primary mission since the mid-1950s has been to create an orderly market for alcoholic beverages free of crime and vice (Morgan, 1980, 1988). Two key ordinances in the $\mathrm{ABC}$ Act guide preventive efforts to mitigate issues among stakeholders concerned about health, safety, and social problems: Do not sell to obviously intoxicated patrons (California ABC Code S. 25602), and do not sell to minors (persons under 21 years of age) (S. 25658).

Neither the ABC Act nor its authorization in the California Constitution (Title XX, Section 22) include specific provisions to protect health and safety in relation to retail alcohol outlets, although the Alcoholic Beverage Control Act charges the agency to "promote temperance" (California ABC Act 2016, p. 32). The ABC is organized to operate on a case-by-case basis for retail alcohol outlets in conjunction with local jurisdictions. The $A B C$ has very few resources or mandates to consider aggregate impacts of retail alcohol outlets. Such concerns are the province of other state agencies and the California AOD community of service providers, advocates, and researchers.

Relation to cities. The ABC supports active participation by local jurisdictions in the licensing process in three ways.

(1) The ABC licensing process defers to local planning and zoning. ABC district offices cooperate closely with local officials to coordinate local zoning reviews with the submission of retail license 
applications according to ABC Act S. 23790: "No retail license shall be issued . . . contrary to a valid zoning ordinance of any city or county.”

(2) ABC shares licensee oversight and enforcement with local law enforcement. ABC field staff and local law enforcement agencies routinely cooperate on all licensing and on enforcement for the most egregious problems. Enforcement of CUP conditions is a local matter.

(3) ABC provides limited support to local government and the public. Until the early 1980s, ABC did not have strong working relationships with local planning departments and community development agencies. Starting in the late 1980s, these relationships began to improve. Most notably the ABC supported local jurisdiction efforts to require Responsible Beverage Service (RBS) training as a local CUP requirement and provided grants to help local police departments enforce state ABC laws.

Alcohol Research Group (ARG). What is now known as the Alcohol Research Group was founded in 1959 to study the social epidemiology of drinking and alcohol problems at the community level and among groups and populations (e.g., Cahalan, 1970; for the history of ARG see Room, 2006, and Lisansky Gomberg, 1997). Funded as a national research center by the federal government (National Institute on Alcohol Abuse and Alcoholism), ARG had resources to explore experiences with alcohol availability at the city and regional level from a combination of social, regulatory, and land-use perspectives.

ARG's focus contributed to studies of local control and $\mathrm{ABC}$ licensing through two lines of inquiry involving a cross-disciplinary team of young researchers. This early work developed through Prevention Research Center into today's multi-faceted research on nexus relationships between retail alcohol outlets (regulation, distribution, design, and operation) and alcohol-related problems (health, safety, and social well-being). Two aspects of this research stimulated development of Level 2 and Level 3 zoning for retail alcohol outlets.

(1) Municipal land-use planning methods applicable to local control for retail alcohol outlets. In the late 1970s, use of local planning/zoning ordinances specifically for preventive regulation of retail alcohol outlets was a brand new field that had yet to receive academic attention and systematic study. Prompted by cities experimenting with Level 2 zoning, Wittman opened this field with (i) papers outlining the research and policy issues (Wittman, 1980, 1982); (ii) exploration of interagency planning for municipal oversight of retail alcohol outlets (Wallack, 1984-85); (iii) study of the extent to which cities were using zoning ordinances to regulate retail alcohol outlets (Wittman \& Hilton, 1987); and (iv) exploration of the construction of a credible and actionable nexus linking alcohol-related problems to retail alcohol outlets (Fillmore \& Wittman, 1982; Wittman, 1982).

(2) Policy studies and legal analyses to investigate state roles and functions for preventive regulation of alcohol availability. ARG provided an extraordinary interdisciplinary environment for explorations of interactions between state $\mathrm{ABC}$ control policies and development of community initiatives to establish local control, producing a number of working papers and publications. For example, Morgan $(1980,1988)$ explored the state ABC's function as mediator for competing interests between stakeholders in the alcoholic beverage industry - the industry's producers, distributors, retailers_and the public. Mosher (1979) explored the California ABC's regulatory authority and operations with respect to protections for public health and safety. Mosher and Wallack explored the regulation of alcoholic beverage advertising (1979a) and evaluated a state ABC-sponsored RBS training program (1979b). (The Prevention Center Website [www:prev.org/pubs_staff] includes an index of papers and publications written by Mosher, Wallack, and Wittman while at ARG).

The Prevention Research Center (PRC) and its spinoffs. In 1983, four researchers from ARG became founding members of the Prevention Research Center (PRC) under the Pacific Institute of Research and Evaluation. PRC, also a national alcohol research center funded by the National Institute on Alcohol Abuse and Alcoholism, is devoted to prevention research through environmental and policyoriented approaches. PRC has established six research lines germane to development of local control in California cities, particularly in the areas of local community planning methods and nexus research. The PRC website includes materials organized by authors shown in parentheses below; each line continues to the present.

- Community prevention planning studies (Wittman)

- $\quad$ Outlet density research (Gruenewald)

- RBS research and behavior related to retail alcohol outlets (Saltz, Wittman and Lee)

- College drinking and community enforcement (Saltz)

- Alcohol control policy and policy advocacy (Mosher)

- Media studies of alcohol advertising and prevention messages (Wallack).

Research originating at ARG and PRC needed to reach 30 million Californians in almost 500 cities. The California DADP provided support for transmitting this work to the field.

California Department of Alcohol and Drug Programs. The California DADP was created in 1979 to consolidate and re-organize alcoholism treatment services that had been fragmented in the wake of state mental hospital closures underway since the 1950s. The DADP established a care system through county alcohol and drug program (county ADP) offices to provide coordinated AOD treatment and recovery services linked to medical, mental health, and social services. Prevention was a major concern for this new agency (Blacksher, 1990, pp. 222): 
In the early $80 \mathrm{~s}$, the social/community model began to impact California's attitudes about prevention efforts. Previously, little effort was spent on developing prevention strategies, since many believed that the disease of alcoholism could not be prevented. When we began to look at the broader scope of alcohol related problems, we began to look at the social and environmental influences on these problems. The Department convened a task force consisting of public health and alcohol program experts and developed a Framework for Community Initiatives for Preventing Alcohol Problems in California. Our prevention strategies from that time have been based on the Framework. Our strategies are built around public policy issues, reduction of environmental risks, community organization, and a variety of educational and information activities. Technical assistance has been provided around the strategies with emphasis on enabling communities to assess their own alcohol-related problems, and then organizing around a plan to reduce these problems.

This Framework served for more than 20 years to help the California AOD field build a community approach to prevention based on environmental approaches, especially support for local control. The state DADP (i) provided a comprehensive development agenda, established through planning conferences involving researchers, officials, and practitioners that helped organize the field, to translate emerging prevention research into practice (Мecca, 1985); (ii) provided training, technical assistance, and consultation to build and disseminate the agenda through a service known as the Community Prevention Initiative; (iii) supported a county ADP training and technical assistance infrastructure for stimulation and transmission of the agenda into practice at the community level; and (iv) provided a channel for federal funds to activate this system. From 1983 through 2005, California communities received strong support from this system to develop community planning and obtain technical assistance and for development of retail alcohol outlet CUPs and DAOs.

Support from county ADP administrators. The state DADP distributes federal funds (described below) to support county ADPs in 58 counties, which provide AOD treatment and prevention services to Californians at the community level. Starting in the mid-1980s about a dozen county ADP administrators adopted community environment approaches to prevention as their primary approach and actively supported local control initiatives. These initiatives were carried out primarily by local nonprofit community prevention service providers on contract to the county ADP. The contract prevention providers provided education and community organizing to help cities adopt Level 2 CUP ordinances for retail alcohol outlets.

Federal support for community environment prevention planning. State DADP funding for local control comes from the federal government (the Center for Substance
Abuse Prevention [CSAP], Alcohol Drugs and Mental Health Services Administration, US Department of Health and Human Services). Funding levels have been adequate since the mid-1990s and give the state DADP considerable flexibility and discretion for use of the funds to support prevention activities. In 2006, CSAP required all states to adopt the Strategic Prevention Framework (SPF) ${ }^{1}$, an evidence-based planning approach. SPF planning is a datadriven, logic-model-based, outcome-oriented planning approach that follows a five-step planning process.

Thus the state DADP offered substantial conceptual and material help to local communities develop preventive local control for retail alcohol outlets. The following discussion reviews cities' adoption of Level 2 and Level 3 zoning ordinances, and the way the California AOD prevention community helped.

What "first wave" cities did and did not accomplish The first wave of Level 2 alcohol outlet CUPs was driven by community reaction to address problems emerging from a rising tide of new or expanded retail alcohol outlets, along with persistent problems from existing "bad apple" outlets. The CUP review process put the brakes on the flow of new outlets, but CUPs had mixed success reducing long-standing problems at existing establishments. Initial successes opened up an agenda for future improvements: The following topics became a do-list to improve local control in light of these initial experiences.

- Modify current zoning practices to improve health and safety of existing ("grandfathered") alcohol outlets.

- Formally document the local nexus between alcohol outlets and alcohol problems.

- Improve local capacity to regulate retail alcohol outlet performance through CUPs.

- Bolster weak implementation of alcohol outlet CUP ordinances.

Unchartered territory changing from permissive zoning to preventive zoning. Alcohol outlet CUPs introduced a new topic-protection of health and safety-into traditional uses of land-use planning and zoning ordinances that controlled only physical features of retail alcohol outlet operation and growth. Prevention planners would need years to grasp the possibilities that had just opened up for preventive alcohol outlet design and safe alcohol management practices.

\section{Progression for development of local control from 1980 to 2015}

Early efforts by pioneering cities opened the way for development of local control as a community prevention planning resource. A four-stage process got underway:

Community action (reactive) zoning (late 1970s). A few pioneering California cities took action through

\footnotetext{
${ }^{1}$ Strategic Prevention Framework available at

http://www.samhsa.gov/capt/applying-strategic-preventionframework
} 
community organizations frustrated with failures of permissive Level 1 laissez-faire zoning for retail alcohol outlets and inadequate post-hoc enforcement by the $\mathrm{ABC}$ and local law enforcement. These exemplary cities pointed the way for preventive local control to manage alcohol outlet growth and to limit problematic operations of retail alcohol outlets. These cities also experienced the limitations of initial efforts noted above.

Community control zoning (CUPs in the 1980s). A statewide movement grew to adopt Level 2 alcohol outlet CUP zoning to (1) limit the flow of new and expanded retail alcohol outlets into the community and (2) establish controls over the setting and its management to protect health and safety. Community action prompted cities to impose CUPs as "fences of good practice" that set limits on location and design of outlets and that imposed operating restrictions to protect outlet occupants and the nearby community. A community planning manual underwritten by the state DADP presented these practices based on case studies of cities that pioneered Level 2 zoning for retail alcohol outlets (Wittman \& Shane, 1988). The manual was widely consulted by county ADPs and circulated to dozens of cities. With strong encouragement from the California AOD prevention community, the number of cities with alcohol outlet Level 2 CUP zoning is estimated to have doubled in the 1980s and 1990 s to cover about $80 \%$ of California cities. The manual and related training and technical assistance provided through the state DADP were viewed as a beginning: Many cities were slow to pursue assertive compliance with Level 2 alcohol outlet CUP conditions; most cities relied on operators to selfenforce CUP conditions with little or no oversight, in effect continuing Level 1 zoning enforcement practices.

Community oversight zoning (DAOs in the 1990s). While cities continued to adopt Level 2 CUPs for alcohol outlets at a steady clip, continuing frustrations with existing outlets led to discovery of the Level 3 Deemed Approved Ordinance (DAO) zoning described in Wittman (2016). DAOs provided a mechanism to apply performance standards for new alcohol outlet CUPs to all retail outlets that created nuisances in the jurisdiction, including "existing nonconforming" grandfathered outlets. The DAO ordinance makes it possible for cities to enforce high standards of operation and design for all outlets according to operational standards in current CUPs. Further, passage of a deemed approved ordinance involved a higher level of community planning that engages all stakeholders (including existing retailers) to negotiate CUP conditions that effectively assert public health and safety concerns in the face of prevalent commercial interests. Adoption of a DAO underscores the need for both extensive community organizing and for a community-wide preventive surveillance system on a continuing basis. Such a system monitors all operating alcohol outlets to scan for incipient problems and allows prompt action to secure conformance and compliance to CUP requirements. This approach emphasizes pro-active oversight (positive adoption of safe alcohol management practices) leading to post-hoc enforcement (reactive problem-solving), which is the next step if compliance efforts are not successful. In the late 1990s and early 2000s cities began experimenting with comprehensive communityenvironment risk documentation systems using local police data, key informant interviews, and community call-in lines.

Community management zoning (Preventive zoning 2000-2015). The previous three stages paved the way for development of a fourth stage of oversight, adding to the tools developed in the first three stages a more holistic community management dimension. The first three stages pursue a problem-solving approach focused on general performance standards (monitored for objective outcomes, such as fewer police calls) to improve operator practice to reduce harms. The fourth stage engages the retail outlet operator in a community partnership that seeks to build preventive performance (prescriptive operating standards) into retail outlet business operations.

This level of community oversight incorporates explicit community standards for preventive performance into alcohol outlet design and operation for sale and service of alcohol. The goal is to merge preventive values (care for customers, respect for the community) with commercial values (sales to customers) in a seamless operation that accomplishes both purposes. One way to envisage this goal is to establish explicit community standards for "five Ps of prevention" - that is, preventive practices for problem-free promotion, pricing, pour policy, patron care, and premises management - that guide retailer conduct for the traditional four Ps of marketing (price, promotion, product, and place) (Wittman, 2013). This entails a level of community oversight that establishes public preventive management for each outlet. Public management holds the owner/manager firmly accountable for following safe practices according to the use permit. Enforcement emphasizes positive compliance first, followed by firm, fair, and prompt sanctions for violations of use-permit conditions and state alcohol laws. Within this exoskeleton of firm community accountability, the owner/operator is encouraged to adopt, willingly and wisely, an alcohol-safe business plan that integrates CUP conditions into a successful business (Rogers et al., 2014).

Community management approaches from 2010-present. This fourth level of preventive public oversight is being formally developed with selected cities by two county AOD prevention programs according to the C-BERR community planning approach mentioned below (Kern County Mental Health Services and Los Angeles County Department of Public Health). Similar approaches are being pursued in perhaps a dozen counties without a formal planning process and without comprehensive AOD environmental risk documentation 
Three lines of development are underway in these counties to help cities transition from problem-oriented oversight zoning to management-oriented preventive zoning:

- Adoption of a purpose-built participatory planning model (based on stakeholder negotiation) that engages the community to establish preventive retail alcohol management practices. Within this city planning discipline (see Minkler \& Wallerstein, 2008), one participatory planning approach designed specifically for community management of AOD availability is the Community-Based Environmental Risk Reduction for Prevention of Alcohol and Drug Problems (the C-BERR approach) (Goldberg \& Wittman, 2005; Wittman, 2007, 2010);

- $\quad$ Creation of a comprehensive local data system that uniformly monitors all AOD risk settings. The C-BERR approach helps each city build its own preventive surveillance system to identify and act promptly on the local alcohol outlet problem-nexus. This local risk-assessment data system provides a sound factual basis for operation of the public local oversight system (CLEW Associates, 2016; Prevention by Design, 2015).

- $\quad$ Application of preventive zoning through a local evidence-based, outcome-oriented planning process based on the community's system for monitoring AOD risk-settings. The C-BERR participatory planning process uses the federallymandated Strategic Prevention Framework (SPF) to launch a local environmental risk-assessment system to adopt efficient and effective preventive local control policies for retail alcohol outlets (Melena \& Wittman, 2015). Fortunately statemandated federal requirements to use the SPF approach to provide resources to both the state and county ADPs to support the process with consultation and technical assistance.

\section{Discussion}

Over the years California cities have greatly increased their capacity to enact Level 2 CUP and Level 3 DAO zoning for retail alcohol outlets. Impressive gains occurred from the mid-1980s until about 2005 when the state DADP and county ADP administrators were especially supportive. Many cities adopted Level 2 CUP zoning and the field discovered Level $3 \mathrm{DAO}$ zoning. We estimate that by the year 2000, about $80 \%$ of California cities enacted CUP zoning for retail alcohol outlets ${ }^{2}$. The decade from 1990 to 2000 saw declines in both absolute numbers and population

\footnotetext{
${ }^{2}$ We estimate doubling the number of cities found by Wittman and Hilton in the early 1980s. Estimate is based on qualitative assessment of requests for assistance and county ADP experiences; the state has no tracking system to monitor adoption and implementation of Level 2 and Level 3 alcohol outlet zoning ordinances.
}

density for all retail alcohol outlets in California: a $4 \%$ decline in total number of retail alcohol outlets and a $16 \%$ decline in the statewide per capita ratio ${ }^{3}$.

Although only cities can enact alcohol outlet zoning ordinances, cities do not act alone. They seek advice from each other and from experts, and they depend on help from state agencies and federal grants. We estimate about half of the state's cities have received some level of training, consultation, technical assistance, and advocacy services through the state DADP technical assistance program and through county ADP support for local organizing to help cities adopt local control. This effort also stimulated involvement by AOD researchers and support from AOD advocates.

Now California is poised to move to a fourth level of local control for retail alcohol availability, preventive zoning. The appropriate planning technologies and local information systems are being worked out in community laboratories supported by select county ADPs and a few dedicated community service programs. This effort can grow and momentum can build since the California AOD prevention infrastructure is intact. County ADPs are poised to participate in expanding pilot work underway, and federal funding is potentially available.

The importance of state DADP support. In 2005, the state DADP suspended a 20-year program of assertive support for local control as the fourth stage (community management through preventive zoning) was getting organized. Local control has been on a plateau since, alive and well but limited to initiatives in a few counties. We believe the time has come to re-assert state support to build these efforts and take them to scale statewide.

Continuing development of preventive local control for retail alcohol availability. Cities continue to need active outside support in four areas:

(1) Continue to build a working model for participatory community prevention planning that is evidence-based, data-driven, and outcome-oriented and that is critiqued and refined as it proceeds.

(2) Continue to build a robust community data system to document the connection of alcohol outlets with community problems and support local planning activities based on logic models to achieve measurable outcomes. Data are readily available locally to document the local epidemiology of AOD risk-settings throughout the community on a preventive surveillance basis (Miller, Tindall, et al., 2014; Prevention by Design, 2015). This argues for developing a state data template that all local jurisdictions can use to support both local planning and cross-jurisdiction research and policy analysis.

(3) Continue to pursue and disseminate to the field research germane to development of a credible nexus

\footnotetext{
${ }^{3}$ Changes are based on population data from state Finance Office; and retail outlets data from the $\mathrm{ABC}$.
} 
in three areas: (i) density research, particularly geobased overconcentration; (ii) community RBS, particularly research focused specifically on preventive alcohol management practices by owner/operators of retail alcohol and city management of RBS training requirements outlets (Hanour, 2013; Rogers et al., 2014; Warpenius, Homila, \& Mustonen, 2010); and (iii) operational factors that predict AODrelated problems, particularly physical/temporal design and premises management (Graham \& Homel, 2008; Wittman, 2012).

(4) Rebuild the advocacy base to support community organizing and the development of policy initiatives at the community level. Earlier cooperative advocacy efforts have declined sharply over the last decade; state-level attention will stimulate this work. Advocacy efforts can be expected to rebound in direct proportion to increases is state-level support for the field.

Resuming state support for local control. The record shows the four development areas above need support from the state for organization and leadership to gain traction with each other and to resume robust growth. The four "estates" of the California AOD community-officials, researchers, advocates, and service providers-rallied well together to face challenges during the ' 80 s and '90s thanks to DADP leadership described earlier. We suggest five action areas to support the developmental efforts identified above in which three state agencies have key roles (Alcoholic Beverage Control Department; Department of Health Care Services/Substance Use Disorders; and Department of Public Health):

- Assess current status of preventive local control in California cities and counties.

- Develop community planning methods to support preventive local control.

- Create a shared data template to support documentation of local AOD risk environments.

- Institute a research-to-practice program to strengthen local control policies and practices.

- Convene state agency partners and statewide organizations to support local control.

In 2013 the state DADP was absorbed into another state agency, Department of Health Care Services (DHCS) Substance Use Disorders Services (SUDS). We believe that if DHCS/SUDS takes the lead to organize state agency support for local control, the supportive California AOD infrastructure built for local control over the last 30 years will respond enthusiastically with a creative spurt that produces new innovations. This infrastructure is still alive and well: Prospects are good that members of the county ADP infrastructure and the other "estates" comprising the California AOD prevention community will rise up to make excellent use of state support. Now is the time for the field to assert itself.

\section{Conclusion}

Hundreds of California cities and towns have successfully adopted preventive local control. Californians are using Level 2 CUP zoning and Level 3 DAO zoning to reduce and minimize problems related to retail alcohol outlets particularly regarding public safety and quality of life issues. This represents genuine progress in harm reduction but is still half a loaf. Although cities deal effectively with visible and prominent retail outlet problems, too often problems reach high levels of visibility and create considerable harm before action is taken. Underlying systemic problems are not addressed, such as the relationship of geo-spatial and economic outlet availability to alcohol-related health problems, and youth access to retail alcohol. Issues of implementation and sustainability are not being adequately addressed.

The courts' acceptance of the DAO zoning ordinance makes it possible to attend to these systemic issues and undertake community initiatives to manage difficult and highly persistent problems with all retail outlets. The DAO introduces a fourth level of preventive zoning that employs participatory planning and system-wide preventive surveillance to identify persistent problems and manage them through land-use limits and compliance measures. Much more can be done to set clear limits on density, location, types, and design of outlets. More can also be done to write standard operating conditions that establish clear accountability for owner/managers. Cities that couple systemic documentation and organizing with passage of a DAO ordinance report impressive reductions in previously intractable problems (Kendrick, 2016).

Thus we conclude that California cities are halfway to realizing their full potential for preventive local control of alcohol availability. We close with a friendly challenge: Will cities remain at current levels of alcohol outlet zoning based on active Level 2 CUP problem-solving and nascent Level 3 DAO oversight? Or will cities adopt nextgeneration preventive zoning that sustainably reduces harms and losses attributable to retail alcohol outlets? Nothing stands in the way; it's up to Californians to decide.

\section{References}

Blacksher, S. (1990). Appendix B: A chronology of the development of the California alcohol program. In S. Shaw \& T. Borkman (Eds.), Social model alcohol recovery (pp. 217-224). Burbank, CA, United States: Bridge-Focus Press.

Cahalan, D. (1970). Problem drinkers. San Francisco, CA, United States: Jossey-Bass.

California ABC Code. California Alcoholic Beverage Control Department. Sacramento, California. Accessed June 24, 2016 at https://www.abc.ca.gov/forms/ABCAct_2016.pdf

CLEW Associates. (2016). ASIPS/GIS community tours: A briefing for LAPD. Alcohol/drug Sensitive Information System in a Geographic Information System format. Berkeley, CA, United States: Author. 
Fillmore, K. M., \& Wittman, F. D. (1982). The effects of availability of alcohol on college students drinking: A trend study. Contemporary Drug Problems, 11(3), 455-492.

Goldberg, A., \& Wittman, F. D. (2005). Taking charge: Managing community alcohol and drug risk environments. Berkeley, CA, United States: Community Prevention Planning Project, Institute for the Study of Social Change.

Graham, K., \& Homel, R. (2008). Raising the bar: Preventing aggression in and around bars, pubs and clubs. Devon, UK: Willan.

Hanour, G. (2013). A business approach to reducing drunk driving. Retrieved from http://www.amazon.com/ Business-Approach-Reducing-Drunk-Driving/

Lisansky Gomberg, E. S. (1997). Don Cahalan: A biographical sketch. Ethnicity and Substance Abuse, 11(1-2), 3-9.

Kendrick, Gary, (May 2016). Powerful local control remedy addresses El Cajon's alcohol nuisance problems. Western City Magazine. Retrieved from http://www.westerncity.com/Western-City/May2016/Powerful-Local-Control-Remedy-Addresses-ElCajons-Alcohol-Nuisance-Problems/

Mecca, A. M. (1985). Prevention action plan for alcoholrelated problems. Belvedere, CA, United States: California Health Research Foundation.

Melena, A., \& Wittman, F. (2015). C-BERR, step-by-step. San Fernando, CA, United States: San Fernando Valley Partnership.

Miller, P., Tindall, J., Groombridge, D., Lecathelinais, Gillham, K., McFarlane, E., ... Wiggers, J. (2014). Effective measures for dealing with alcohol and the night-time economy (DANTE). In: E. Manton, R. Room, C. Giorgi, \& M. Thorn, (Eds.), Stemming the tide of alcohol: Liquor licensing and the public interest, pp. 196-210, Canberra: Foundation for Alcohol Research and Education.

Minkler, M., \& Wallerstein, N. (Eds.). (2008). Part five: Using CBPR to promote social change and healthy public policy. In M. Minkler \& N. Wallerstein (Eds.), Community-based participatory research: From process to outcomes (pp. 307-370). San Francisco, CA, United States: Jossey-Bass.

Morgan, P. A. (1980). The state as mediator: Alcohol problem management in the postwar period. Contemporary Drug Problems, 9(1), 107-140.

Morgan, P. A. (1988). Power, politics and public health: The political power of the alcohol beverage industry. Journal of Public Health Policy, 9, 177-197.

Mosher, J. F. (1979, February). The alcoholic beverage control system in California. Prepared for the Second Plenary Meeting of the International Study of Alcohol Control Experiences, Pacific Grove, CA, United States.

Mosher, J. F., \& Wallack, L. (1979a). Proposed reforms in the regulation of alcoholic beverage advertising. Contemporary Drug Problems, 8(1), 87-106.

Mosher, J. F., \& Wallack, L. (1979b). The DUI project. Contemporary Drug Problems, 8(2), 193-206.

Prevention by Design. (2015, March 17). Community reconnaissance to identify Delano high-risk AOD environments. Briefing memo prepared for Kern County Mental Health Services Alcohol and Drug Program. Berkeley, CA, United States: CLEW Associates.

Rogers, P., Griffin, M., Kendrick, K., Bloch, S., Hanour, G., \& Wittman, F. (2014, August 11-13). Responsible Beverage Service training as a community prevention resource. Presented at the Substance Use Disorders Statewide Conference, Costa Mesa, CA, United States.

Room, R. (2006). Genevieve Knupfer, 1914-2005: Turning presumption into researchable questions. Addiction, 101(5), 746-747.

Wallack, L. (1984-85). A community approach to the prevention of alcohol-related problems: The San Francisco experience. International Quarterly of Community Health Education, 5(2), 85-102.

Warpenius, K., Homila, M., \& Mustonen, H. (2010). Effects of a community intervention to reduce the serving of alcohol to intoxicated patrons. Addiction, 105, 1032-1040.

Wittman, F. D. (1980). Tale of two cities: Policies and practices in local control of alcohol availability. Berkeley, CA, United States: Social Research Group.

Wittman, F. D. (1982). Zoning ordinances, alcohol outlets, and planning: Prospects of local control of alcohol problems. Berkeley, CA, United States: Alcohol Research Group.

Wittman, F. D. (2007). Community control of alcohol and drug risk environments: The California experience. Substance Use \& Misuse, 42(12), 1835-1849.

Wittman, F. D. (2010). Community-based environmental risk reduction (C-BERR) for prevention of alcohol and other drug problems: Concepts and strategies. Berkeley, CA, United States: CLEW Associates.

Wittman, F. D. (2012, October). Restaurants that "morph" into bars and nightclubs in California Communities: What's the problem and what can be done about it? Santa Rosa, CA, United States: Center for Applied Research Solutions.

Wittman, F. D. (2013, February 27). Orange County cities Responsible Beverage Services training. Presentation to Orange County DUI Summit, Berkeley, CA, United States.

Wittman, F. D. (2016). Halfway there - The evolution of local alcohol control in California: Part I. The system as it has developed. International Journal of Alcohol and Drug Research, 5(3), 101-107.

Wittman, F. D., \& Hilton, M. E. (1987). Uses of planning and zoning ordinances to regulate alcohol outlets in California cities. In H. Holder (Ed.), Control issues in alcohol abuse prevention: Strategies for states and communities (pp. 337-366). Greenwich, CT, United States: JAI Press.

Wittman, F. D., \& Shane, P. (1988). Manual for community planning to prevent problems of alcohol availability. Berkeley, CA, United States: Prevention Research Center, Pacific Institute for Research and Evaluation. 